\title{
A Novel Antibacterial Dental Resin Composite
}

\author{
Yiming Weng ${ }^{1}$, Voon J. Chong ${ }^{1}$, Leah Howard ${ }^{1}$, Ruijie Huang ${ }^{2}$, Richard L. Gregory ${ }^{2}$, Dong Xie ${ }^{*}$ \\ ${ }^{1}$ Department of Biomedical Engineering, Purdue School of Engineering and Technology, Indiana University-Purdue University at \\ Indianapolis, Indianapolis, USA; ${ }^{2}$ Department of Oral Biology, School of Dentistry, Indiana University, Indianapolis, USA. \\ Email: *dxie@iupui.edu
}

Received January $12^{\text {th }}, 2012$; revised February $20^{\text {th }}, 2012$; accepted March $10^{\text {th }}, 2012$

\begin{abstract}
This study reports the synthesis and evaluation of a novel furanone-containing antibacterial resin composite. Compressive strength (CS) and S. mutans viability were used to evaluate the mechanical strength and antibacterial activity of the composites. With $5 \%$ to $30 \%$ addition of the furanone derivative, the composite showed no change in CS but a significant antibacterial activity with a $16 \%-68 \%$ reduction in the $S$. mutans viability. Further, the antibacterial activity of the modified composite was not affected by human saliva. The aging study implies that the modified composite may have a long-lasting antibacterial function. Within the limitations of this study, it appears that this experimental resin composite may potentially be developed into a clinically attractive dental restorative due to its high mechanical strength and antibacterial function.
\end{abstract}

Keywords: Furanone Derivative; Antibacterial; Resin Composite; CS; S. mutans Viability

\section{Introduction}

Long-lasting restoratives and restoration are clinically attractive because they can reduce patents' pain and expense as well as the number of their visits to dental offices [1-4]. In dentistry, both restorative materials and oral bacteria are believed to be responsible for the restoration failure [2]. Secondary caries is found to be the main reason to the restoration failure of dental restoratives including resin composites and glass-ionomer cements [1-4]. Secondary caries that often occurs at the interface between the restoration and the cavity preparation is primarily caused by demineralization of tooth structure due to invasion of plaque bacteria (acid-producing bacteria) such as Streptococcus mutans (S. mutans) in the presence of fermentable carbohydrates [4]. To make long-lasting restorations, the materials should be made antibacterial. Although numerous efforts have been made on improving antibacterial activities of dental restoratives, most of them have been focused on release or slow-release of various incorporated low molecular weight antibacterial agents such as antibiotics, zinc ions, silver ions, iodine and chlorhexidine [5-9]. Yet release or slow-release can lead or has led to a reduction of mechanical properties of the restoratives over time, shortterm effectiveness, and possible toxicity to surrounding tissues if the dose or release is not properly controlled [5-9]. Materials containing quaternary ammonium

${ }^{*}$ Corresponding author. salt (QAS) or phosphonium salt groups have been studied extensively as an important antimicrobial material and used for a variety of applications due to their potent antimicrobial activities [10-14]. These materials are found to be capable of killing bacteria that are resistant to other types of cationic antibacterials [15]. The examples of the QAS-containing materials as antibacterials for dental restoratives include incorporation of a methacryloyloxydodecyl pyridinium bromide as an antibacterial monomer into resin composites [12], use of methacryloxylethyl cetyl ammonium chloride as a component for antibacterial bonding agents [16,17], and incorporation of quaternary ammonium polyethylenimine nanoparticles into resin composites [18,19]. All these studies found that the QAS-containing materials did exhibit significant antibacterial activities. However, our recent study found that incorporation of QAS into dental resin composites can significantly decrease mechanical strengths due to its strong hydrophilic characteristics, if the amount added is beyond a certain limit [20]. In addition, it has been reported that human saliva can significantly reduce the antibacterial activity of the QAS-containing restoratives, probably due to electrostatic interactions between QAS and proteins in saliva [21-22]. Recently furanone derivatives have been found to have strong antitumor [23] and antibacterial functions [24]. In the study, we would like to explore them in dental applications.

This paper reports the synthesis of a novel furanone derivative and the effect of this synthesized furanone 
derivative on the antibacterial activity and compressive strength of the dental resin composite.

\section{Materials and Methods}

\subsection{Materials}

Bisphenol A glycerolate dimethacrylate (BisGMA), Bisphenol A ethoxylate dimethacrylate (BisEMA), urethane dimethacrylate (UDMA), triethylene glycol dimethacrylate (TEGDMA), dl-camphoroquinone (CQ), 2(dimethylamino)ethyl methacrylate (DMAEMA), toluene, acryloyl chloride (AC), 3,4-dichloromalealdehydic acid (DA), ethyl acetate and sodium bicarbonate were used as received from Sigma-Aldrich Co. (Milwaukee, WI) without further purifications. The untreated glass fillers from Herculite XRV (0.7 microns) were used as received from Sybron Dental Specialties (Newport Beach, CA).

\subsection{Synthesis and Characterization}

The new monomer, 5-acryloyloxy-3,4-dichlorocrotonolactone (AD), was prepared from the reaction of 3,4dichloromalealdehydic acid (DA) with acryloyl chloride (AC) in the presence of toluene at $90^{\circ} \mathrm{C}-100^{\circ} \mathrm{C}$ for $3-4$ h. After toluene was removed, the residue was washed with sodium bicarbonate and distilled water, followed by extracting with ethyl acetate. AD was purified by completely removing ethyl acetate. The synthesis scheme is shown in Figure 1. The chemical structure of the synthesized $\mathrm{AD}$ and starting chemicals was characterized by Fourier transform-infrared (FT-IR) spectroscopy and nuclear magnetic resonance (NMR) spectroscopy. The proton NMR (1HNMR) spectra were obtained on a 500 $\mathrm{MHz}$ Bruker NMR spectrometer (Bruker Avance II, Bruker BioSpin Corporation, Billerica, MA) using deuterated dimethyl sulfoxide and chloroform as solvents and FT-IR spectra were obtained on a FT-IR spectrometer (Mattson Research Series FT/IR 1000, Madison, WI).

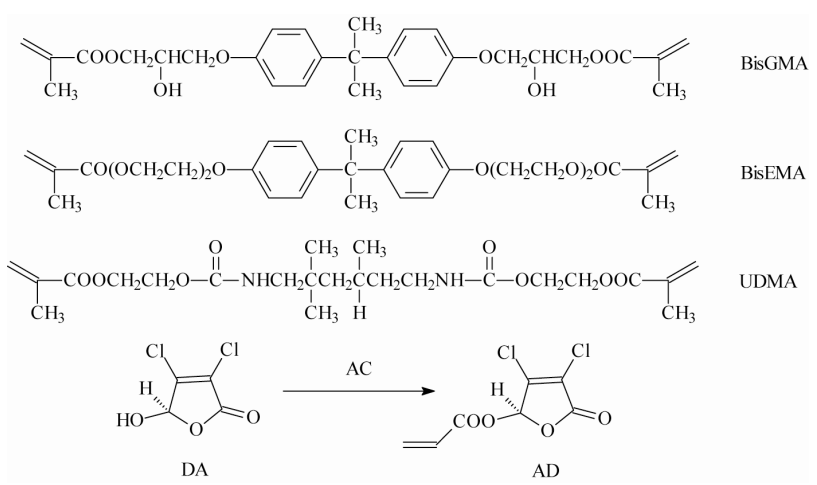

Figure 1. Schematic diagram for the structures of the oligomers used in the study and synthesis of AD from the reaction of DA with AC.

\subsection{Preparation of Specimens}

The antibacterial resin composite was prepared as described previously [20]. Briefly, the composite was formulated with a two-component system (liquid and powder). The liquid was formulated with CQ (photo-initiator, $1 \%$ by weight), DMAEMA (activator, $2 \%$ ), AD, BisGMA, UDMA and BisEMA, where AD/a mixture $($ BisGMA/UDMA/BisEMA $=1: 1: 1$, by weight $)=0 \%$, $5 \%, 10 \%, 20 \%, 30 \%, 40 \%, 50 \%$ and $70 \%$ (by weight). The schematic structures of BisGMA, BisEMA and UDMA are shown in Figure 1. The untreated glass powders (Herculite XRV, 0.7 microns) were used as fillers and treated with $\gamma$-(trimethoxysilyl)propyl methacrylate as described else- where [20]. A filler level at 75\% (by weight) was used throughout the study. After mixing, the composite was filled into glass tubing to form a cylindrical specimen (4 $\mathrm{mm}$ in diameter by $8 \mathrm{~mm}$ in length) for $\mathrm{CS}$ and a disk- shape specimen ( $4 \mathrm{~mm}$ in diameter by 2 $\mathrm{mm}$ in depth) for antibacterial tests. Specimens were exposed to blue light (EXAKT 520 Blue Light Polymerization Unit, EXACT Technologies, Oklahoma City, OK, USA) for $2 \mathrm{~min}$.

\subsection{Strength and Viscosity Measurement}

The CS test was performed on a screw-driven mechanical tester (QTest QT/10, MTS Systems Corporation, Eden Prairie, MN, USA) with a crosshead speed of 1 $\mathrm{mm} / \mathrm{min}$. The sample sizes were $\mathrm{n}=6-8$ for each formulation. CS was calculated using an equation of $\mathrm{CS}=$ $\mathrm{P} / \pi \mathrm{r}^{2}$, where $\mathrm{P}=$ the load at fracture and $\mathrm{r}=$ the radius of the cylinder. The viscosity of the formulated liquid was determined at $23^{\circ} \mathrm{C}$ using a cone/plate viscometer (RVDVII + CP, Brookfield Eng. Lab. Inc., MA, USA), as described elsewhere [25].

\subsection{Antibacterial Test}

The antibacterial test was conducted following the published procedures [20]. S. mutans was used to evaluate the antibacterial activity of the studied composites. Briefly, colonies of $S$. mutans were suspended in $5 \mathrm{~mL}$ of tryptic soy broth (TSB), supplemented with 1\% sucrose, to make a suspension with $108 \mathrm{CFU} / \mathrm{mL}$ of $S$. mutans, after $24 \mathrm{~h}$ incubation. Specimens pretreated with ethanol $(10 \mathrm{~s})$ were incubated with $S$. mutans in TSB at $37^{\circ} \mathrm{C}$ for $48 \mathrm{~h}$ under $5 \% \mathrm{CO}_{2}$. After equal volumes of the red and the green dyes (LIVE/DEAD BacLight bacterial viability kit L7007, Molecular Probes, Inc., Eugene, OR, USA) were combined in a microfuge tube and mixed thoroughly for $1 \mathrm{~min}, 3 \mu \mathrm{L}$ of the dye mixture was added to $1 \mathrm{~mL}$ of the bacteria suspension, mixed by vortexing for $10 \mathrm{~s}$, sonicating for $10 \mathrm{~s}$ as well as vortexing for another $10 \mathrm{~s}$, and kept in dark for about $15 \mathrm{~min}$, prior to analysis. Then 20 $\mu \mathrm{L}$ of the stained bacterial suspension was analyzed us- 
ing a fluorescent microscope (Nikon Microphot-FXA, Melville, NY, USA). Triple replica was used to obtain a mean value for each material. For evaluation of the saliva effect, human saliva (obtained from a healthy volunteer) was centrifuged for $15 \mathrm{~min}$ at $12,000 \mathrm{~g}$ to remove debris [21]. After the supernatant was filtered with a $0.45 \mu \mathrm{m}$ sterile filter, the filtrate was stored in a freezer $\left(-20^{\circ} \mathrm{C}\right)$ prior to testing. The sterilized composite specimen was incubated in a small tube containing $1 \mathrm{ml}$ of saliva at 37 $\mathrm{oC}$ for $2 \mathrm{~h}$ [21], followed by placing in $5 \mathrm{ml}$ TSB supplemented with $1 \%$ sucrose. The rest of the procedures were the same as above.

\subsection{Aging of the Specimens}

The specimens for both CS and antibacterial activity aging tests were conditioned in distilled water at $37^{\circ} \mathrm{C}$ for 1 day, 3 days and 7 days, followed by direct testing for CS (see 2.4) and incubating with $S$. mutans for $48 \mathrm{~h}$ for antibacterial testing (see 2.5 ).

\subsection{Statistical Analysis}

One-way analysis of variance (ANOVA) with the post hoc Tukey-Kramer multiple-range test was used to determine significant differences of both CS and antibacterial tests among the materials in each group. A level of $\alpha$ $=0.05$ was used for statistical significance.

\section{Results and Discussion}

Furanone-containing materials are reported to have a broad range of biological and physiological properties including antitumor, antibiotic, haemorrhagic and insecticidal activity [23-26]. The biological mechanism of these derivatives is still under investigation [24]. To ex- plore the application of these compounds in dental research, we synthesized a photocurable furanone derivative and applied it to dental resin composites.

Table 1 shows characteristic peaks for DA, AC and AD from both FT-IR and 1HNMR spectra. For FT-IR, the disappearance of the peak at 3362 for pseudo hydroxyl group on DA and appearance of the new peaks at 1807, 1764, 1500, 804 and 670 for both carbonyl and $\mathrm{C}=\mathrm{C}$ groups on acrylate confirmed the formation of $\mathrm{AD}$. For $1 \mathrm{HNMR}$, the disappearance of the chemical shift at $3.45(-\mathrm{OH})$ and all the chemical shifts towards a high field confirmed the formation of AD.

Figure 2 shows the effect of the AD content on CS and $S$. mutans viability of the experimental composite. For CS, the AD addition did not change the CS of the composite until reaching $40 \%$. From $40 \%$ to $70 \%$, CS decreased $11 \%-27 \%$ of its original value. For the $S$. mutans viability, increasing the AD content significantly decreased the $S$. mutans viability. The mean viability values were from 82 to $1 \%$ with 5 to $70 \% \mathrm{AD}$ addition, where all the values were significantly different from each other $(p<0.05)$. The result indicates that this new furanone derivative has potent antibacterial activity. In addition, if we incorporate it within $30 \%-40 \%$, the CS of the resin composite can be kept nearly unchanged. During the course of study, we also found that the viscosity $(154 \mathrm{cp})$ of $\mathrm{AD}$ was similar to that $(132 \mathrm{cp})$ of TEGDMA. Therefore we decided to use AD to replace TEGDMA (a major component currently used in most commercial resin composites), to avoid a significant change in viscosity and possibly subsequent changes in other properties. The formulation with $30 \% \mathrm{AD}$ addition in a mixture of BisGMA, BisEMA and UDMA showed a viscosity of $384(\mathrm{cp})$, which is similar to that (345 cp) for the BisGMA/TEGDMA (50/50) mixture (a formulation

Table 1. The characteristic peaks from FT-IR and ${ }^{1}$ HNMR spectra.

\begin{tabular}{|c|c|}
\hline Material & The characteristic peaks from FT-IR or $1 \mathrm{HNMR}$ \\
\hline \multicolumn{2}{|r|}{ The characteristic peaks $\left(\mathrm{cm}^{-1}\right)$ from FT-IR } \\
\hline $\mathrm{DA}$ & $\begin{array}{l}3362(\mathrm{O}-\mathrm{H} \text { stretching on }-\mathrm{OH}), 1766(\mathrm{C}=\mathrm{O} \text { stretching on carbonyl group }), 1644(\mathrm{C}=\mathrm{C} \text { stretching on internal } \mathrm{C}=\mathrm{C}), 1332,1237 \text { and } 949 \\
(\mathrm{C}-\mathrm{O}-\mathrm{C} \text { stretching on pseudo ester }), 1451,1026 \text { and } 778(\mathrm{O}-\mathrm{H} \text { deformation on pseudo }-\mathrm{OH}), 1279,1118,889 \text { and } 602(\mathrm{C}-\mathrm{O} \text { stretching } \\
\text { on pseudo } \mathrm{C}-\mathrm{OH}), 746(\mathrm{C}-\mathrm{Cl} \text { stretching })\end{array}$ \\
\hline $\mathrm{AC}$ & $\begin{array}{l}1758(\mathrm{C}=\mathrm{O} \text { stretching on carbonyl group }), 1610(\mathrm{C}=\mathrm{C} \text { stretching }), 1395 \text { and } 1145(\mathrm{C}-\mathrm{H} \text { deformation on }-\mathrm{C}=\mathrm{C}-\mathrm{group}), 1284,1074,935 \\
\text { and } 606(\mathrm{C}-\mathrm{O} \text { stretching on carbonyl group), } 971 \text { and } 755(\mathrm{C}-\mathrm{H} \text { out of plane vibration on }-\mathrm{C}=\mathrm{C}), 705(\mathrm{C}-\mathrm{Cl} \text { stretching })\end{array}$ \\
\hline $\mathrm{AD}$ & $\begin{array}{l}1807 \text { and } 1764(\mathrm{C}=\mathrm{O} \text { stretching on carbonyl groups of both pseudo ester and acrylate }), 1639(\mathrm{C}=\mathrm{C} \text { stretching on acrylate and internal } \\
\mathrm{C}=\mathrm{C}), 1500(\mathrm{C}-\mathrm{O}-\mathrm{C} \text { deformation on newly formed ester }), 1407 \text { and } 1137(\mathrm{C}-\mathrm{H} \text { deformation on } \mathrm{C}=\mathrm{C} \text { from acrylate }), 1330 \text { and } 1232 \\
(\mathrm{C}-\mathrm{O}-\mathrm{C} \text { stretching on pseudo ester }), 1295,1068,934 \text { and } 608(\mathrm{C}-\mathrm{O} \text { stretching on carbonyl group }), 985(\mathrm{C}-\mathrm{H} \text { out of plane vibration on } \\
-\mathrm{C}=\mathrm{C}), 889(\mathrm{C}-\mathrm{O} \text { stretching on newly formed ester }), 804 \text { and } 670(\mathrm{C}-\mathrm{H} \text { vibration on newly formed } \mathrm{C}=\mathrm{C} \text { group }), 745(\mathrm{C}-\mathrm{Cl} \text { stretching } \\
\text { on } \mathrm{Cl}-\mathrm{C}=\mathrm{C} \text { group). }\end{array}$ \\
\hline \multicolumn{2}{|r|}{ The characteristic chemical shifts (ppm) from ${ }^{1} \mathrm{HNMR}$} \\
\hline DA & $6.25(-\mathrm{CH})$ and $3.45(-\mathrm{OH})$ \\
\hline $\mathrm{AC}$ & $6.21,6.05$ and $5.82(\mathrm{H} 2 \mathrm{C}=\mathrm{CH}-)$ \\
\hline $\mathrm{AD}$ & $7.20(-\mathrm{CH}), 6.55,6.30$ and $6.15(\mathrm{H} 2 \mathrm{C}=\mathrm{CH}-)$ \\
\hline
\end{tabular}




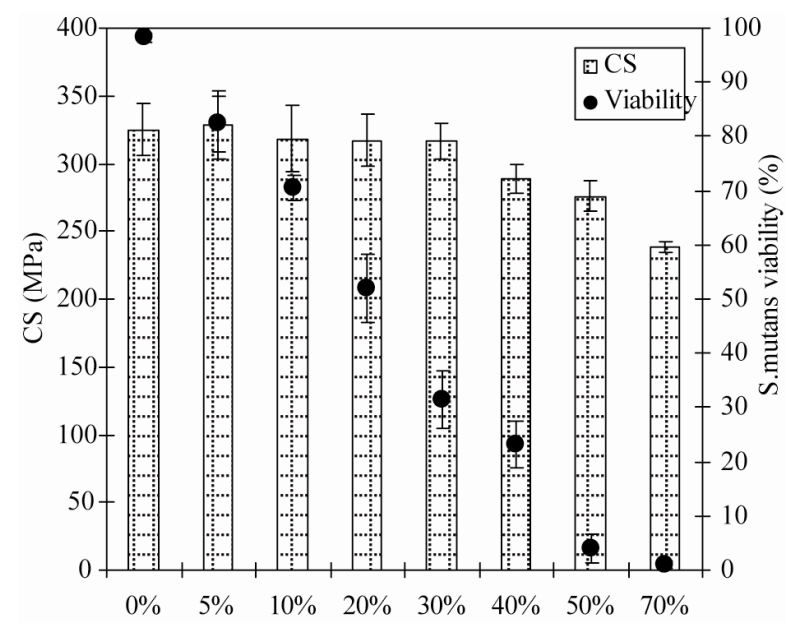

Figure 2. Effect of the AD content on CS and the $S$. mutans viability of the experimental composite: $A D$ content $(\%$, by weight $)=\mathrm{AD} /(\mathrm{AD} / \mathrm{BisGMA} / \mathrm{UDMA} / \mathrm{BisEMA})$, where BiSGMA/UDMA/BisEMA = 1:1:1 (by weight); The filler/resin ratio $=75 \%$ (by weight). For CS, specimens were used directly for the testing. For the $S$. mutans viability, specimens were incubated with $S$. mutans before antibacterial testing.

currently being used in commercial dental composites). This result might possibly help minimize shrinkage and exotherm for this new antibacterial resin composite.

Figure 3 shows the effect of human saliva on the $S$. mutans viability after culturing with the modified composite. No statistically significant differences in the $S$. mutans viability were found between the composites with and without human saliva treatment. It was reported that saliva can significantly reduce the antibacterial activity of the QAS or PQAS-containing materials based on the mechanism of contact inhibition [21,22]. Due to saliva coating or protein film formation on the antibacterial surface of the material, the antibacterial capability became less effective $[21,22]$. The reduction was attributed to the interaction between positive charges on QAS or PQAS and amphiphilic protein macromolecules in saliva. Unlike QAS or PQAS, AD does not carry any charges. That may be why the AD-modified resin composite did not show any reduction in antibacterial activity after treating with saliva.

Figure 4 shows the effect of the modified composite aging in water on CS and S. mutans viability. After 7-day aging in water, all the composite specimens with $\mathrm{AD}$ addition showed no statistically significant differences in either CS or $S$. mutans viability from one another ( $p>$ 0.05 ). It is known that dental resin composites show a certain degree of degradation due to water sorption caused by two hydroxyl groups pendent on BisGMA and three $-\mathrm{CH}_{2} \mathrm{CH}_{2} \mathrm{O}$ - units on TEGDMA [27]. The absorbed water can hydrolyze the silane bond that is used to couple resin with fillers, de-bond the resin-filler interface and thus reduce the mechanical strengths with time [27].

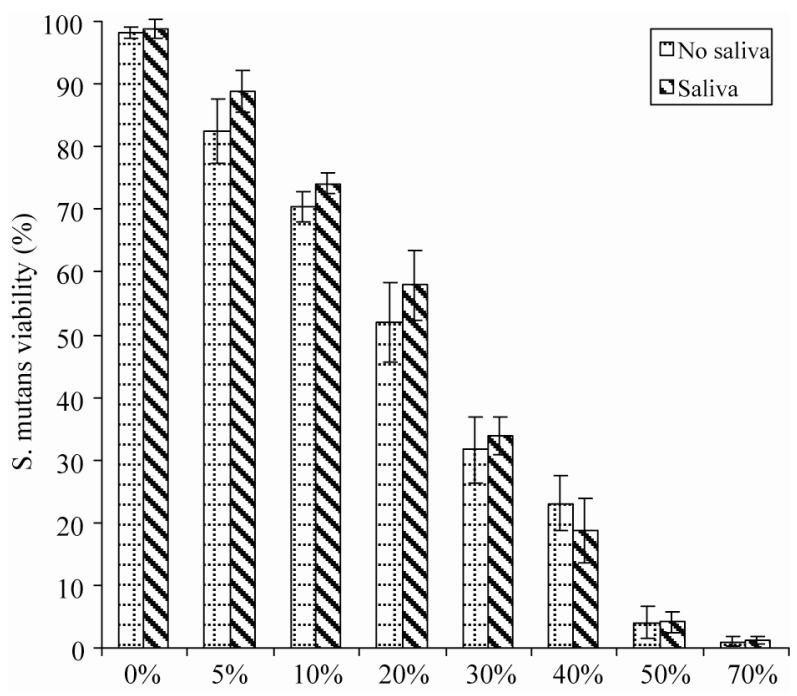

Figure 3. Effect of human saliva on the $S$. mutans viability after culturing with the composites: The formulations were the same as those described in Figure 2. Specimens were soaked in human saliva at $37^{\circ} \mathrm{C}$ for $2 \mathrm{~h}$, followed by incubating with $S$. mutans before antibacterial testing.

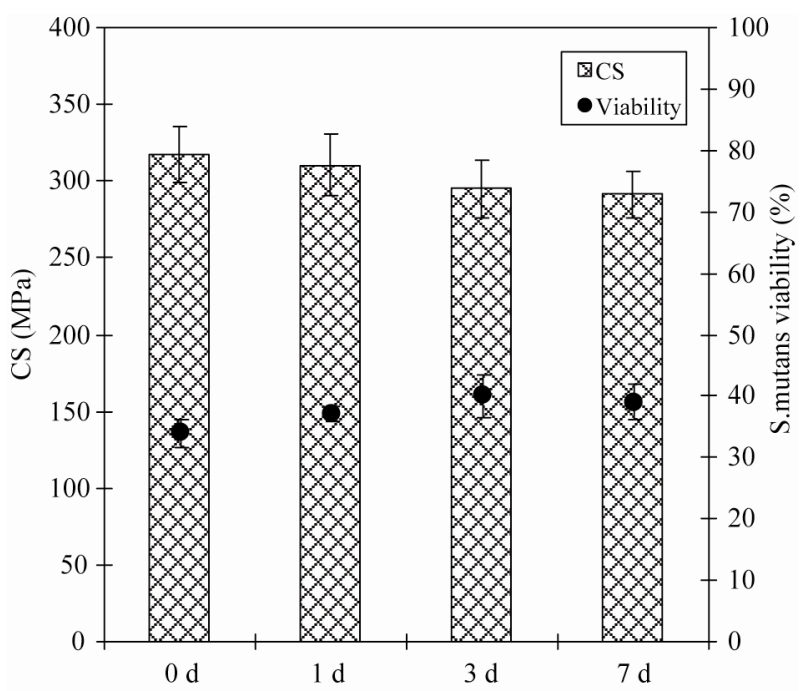

Figure 4. Effect of aging on CS and the $S$. mutans viability of the experimental composite: The formulation was the same as those described in Figure 2, except for AD content $=30 \%$. Specimens were conditioned in distilled water at $37^{\circ} \mathrm{C}$ for 1,3 and 7 days prior to testing.

Our previous study found that using QAS to modify the resin composite could significantly decrease CS probably due to strong hydrophilic nature of the QAS incorporated [20]. The ionic charges on QAS or PQAS can accelerate the interfacial de-bonding [20]. However, the furanone derivative-modified resin composite did not show any statistically noticeable change in CS, indicating that the newly synthesized antibacterial furanone derivative seems more suitable to formulating resin composites than antibacterial QAS [20], probably due to the hydrophobicity 
of the former. The result might also imply that the ADmodified resin composite can has a long-lasting antibacterial function, because otherwise the composite would lose its $\mathrm{CS}$ if $\mathrm{AD}$ was leachable.

\section{Conclusion}

Our future studies will include evaluation of other mechanical and physical properties and biocompatibility of the experimental composite. In conclusion, we have developed a novel antibacterial dental resin composite with comparable mechanical strength and long-lasting antibacterial function. Within the limitations of this study, the developed experimental resin composite may be clinically attractive because all dental restoratives need to be long-lasting.

\section{Acknowledgements}

This work was sponsored by NIH challenge grant (RC1) DE020614

\section{REFERENCES}

[1] I. A. Mjor, J. E. Dahl and J. E. Moorhead, "Placement and Replacement of Restorations in Primary Teeth," Acta Odontologica Scandinavica, Vol. 60, No. 1, 2002, pp. 2528.

[2] H. Forss and E. Widstrom, "Reasons for Restorative Therapy and Longevity of Restorations in Adults," Acta Odontologica Scandinavica, Vol. 62, No. 2, 2004, pp. 8286.

[3] J. Manhart, F. Garcia-Godoy and R. Hickel, "Direct Posterior Restorations: Clinical Results and New Developments," Dental Clinics of North America, Vol. 46, No. 2, 2002, pp. 303-339. doi:10.1016/S0011-8532(01)00010-6

[4] V. Deligeorgi, I. A. Mjor and N. H. Wilson, "An Overview of Reasons for the Placement and Replacement of Restorations," Primary Dental Care, Vol. 8, No. 1, 2001, pp. 5-11. doi:10.1308/135576101771799335

[5] R. G. Craig and J. M. Power, "Restorative Dental Materials," 11th Edition, Mosby-Year Book Inc., St Louis, 2002.

[6] A. Wiegand, W. Buchalla and T. Attin, "Review on Fluoride-Releasing Restorative Materials-Fluoride Release and Uptake Characteristics, Antibacterial Activity and Influence on Caries Formation," Dental Materials, Vol. 23, No. 3, 2007, pp. 343-362.

doi:10.1016/j.dental.2006.01.022

[7] P. W. Osinaga, R. H. Grande, R. Y. Ballester, M. R. Simionato, C. R. D. Rodrigues and A. Muench, "Zinc Sulfate Addition to Glass-Ionomer-Based Cements: Influence on Physical and Antibacterial Properties, Zinc and Fluoride Release," Dental Materials, Vol. 19, No. 3, 2003, pp. 212-217. doi:10.1016/S0109-5641(02)00032-5

[8] Y. Takahashi, S. Imazato, A. V. Kaneshiro, S. Ebisu, J. E. Frencken, F. R. Tay, "Antibacterial Effects and Physical Properties of Glass-Ionomer Cements Containing Chlor- hexidine for the ART Approach," Dental Materials, Vol. 22, No. 7, 2006, pp. 467-452.

doi:10.1016/j.dental.2005.08.003

[9] K. Yamamoto, S. Ohashi, M. Aono, T. Kokubo, I. Yamada and J. Yamauchi, "Antibacterial Activity of Silver Ions Implanted in $\mathrm{SiO}_{2}$ Filler on Oral Streptococci," Dental Materials, Vol. 12, No. 4, 1996, pp. 227-229.

[10] T. Syafiuddin, H. Hisamitsu, T. Toko, T. Igarashi, N. Goto, A. Fujishima and T. Miyazaki, "In Vitro Inhibition of Caries Around a Resin Composite Restoration Containing Antibacterial Filler," Biomaterials, Vol. 18, No. 15, 1997, pp. 1051-1057. doi:10.1016/S0142-9612(97)88072-6

[11] B. Gottenbos, H. C. van der Mei, F. Klatter, P. Nieuwenhuis and H. J. Busscher, "In Vitro and in Vivo Antimicrobial Activity of Covalently Coupled Quaternary Ammonium Silane Coatings on Silicone Rubber," Biomaterials, Vol. 23, No. 6, 2002, pp. 1417-1423. doi:10.1016/S0142-9612(01)00263-0

[12] P. Thebault, E. T. de Givenchy, R. Levy, Y. Vandenberghe, F. Guittard and S. Geribaldi, "Preparation and Antimicrobial Behaviour of Quaternary Ammonium Thiol Derivatives Able to Be Grafted on Metal Surfaces," European Journal of Medicinal Chemistry, Vol. 44, No. 2, 2009, pp. 717-724. doi:10.1016/j.ejmech.2008.05.007

[13] S. Imazato, R. R. Russell and J. F. McCabe, "Antibacterial Activity of MDPB Polymer Incorporated in Dental Resin," Journal of Dentistry, Vol. 23, No. 3, 1995, pp. 177-181. doi:10.1016/0300-5712(95)93576-N

[14] H. Murata, "Permanent, Non-Leaching Antibacterial Surfaces - 2: How High Density Cationic Surfaces Kill Bacterial Cells," Biomaterials, Vol. 28, No. 32, 2007, pp. 4870-4879. doi:10.1016/j.biomaterials.2007.06.012

[15] G. Q. Lu, D. C. Wu and R. W. Fu, "Studies on the Synthesis and Antibacterial Activities of Polymeric Quarternary Ammonium Salts from Dimethylaminoethyl Methacrylate," Reactive and Functional Polymers, Vol. 67, No. 4, 2007, pp. 355-366. doi:10.1016/j.reactfunctpolym.2007.01.008

[16] S. B. Lee, R. R. Koepsel, S. W. Morley, K. Matyjaszewski, Y. Sun and A. J. Russell, "Permanent, Nonleaching Antibacterial Surfaces. 1. Synthesis by Atom Transfer Radical Polymerization," Biomacromolecules, Vol. 5, No. 3, 2004, pp. 877-882. doi:10.1021/bm034352k

[17] F. Li, Z. G. Chai, M. N. Sun, F. Wang, S. Ma, L. Zhang, M. Fang and J. H. Chen, "Anti-Biofilm Effect of Dental Adhesive with Cationic Monomer," Journal of Dental Research, Vol. 88, No. 4, 2009, pp. 372-376. doi:10.1177/0022034509334499

[18] F. Li, J. Chen, Z. Chai, L. Zhang, Y. Xiao, M. Fang and S. Ma, "Effects of a Dental Adhesive Incorporating Antibacterial Monomer on the Growth, Adherence and Membrane Integrity of Streptococcus mutans," Journal of Dentistry, Vol. 37, No. 4, 2009, pp. 289-296. doi:10.1016/j.jdent.2008.12.004

[19] N. Beyth, I. Yudovin-Farber, R. Bahir, A. J. Domb and E. I. Weiss, "Antibacterial Activity of Dental Composites Containing Quaternary Ammonium Polyethylenimine Nanoparticles against Streptococcus mutans," Biomate- 
rials, Vol. 27, No. 21, 2006, pp. 3995-4002. doi:10.1016/j.biomaterials.2006.03.003

[20] Y. Weng, X. Guo, V. J. Chong, L. Howard, R. L. Gregory and D. Xie, "Synthesis and Evaluation of a Novel Antibacterial Dental Resin Composite with Quaternary Ammonium Salts," Journal of Biomechanical Science and Engineering, Vol. 4, No. 3, 2011, pp. 147-157. doi:10.4236/jbise.2011.43021

[21] S. Imazato, N. Ebi, Y. Takahashi, T. Kaneko, S. Ebisu and R. R. B. Russell, "Antibacterial Activity of Bactericide-Immobilized Filler for Resin-Based Restoratives," Biomaterials, Vol. 24, No. 20, 2003, pp. 3605-3609. doi:10.1016/S0142-9612(03)00217-5

[22] N. Ebi, S. Imazato, Y. Noiri and S. Ebisu, "Inhibitory Effects of Resin Composite Containing Bactericide-Immobilized Filler on Plaque Accumulation," Dental Materials, Vol. 17, No. 6, 2001, pp. 485-491. doi:10.1016/S0109-5641(01)00006-9

[23] J. H. Jung, S. Pummangura, C. Chaichantipyuth, C. Patarapanich, P. E. Fanwick, C. J. Chang and J. L. Mclaughlin,
"New Bioactive Heptenes from melodorum fruticosum (Annonaceae)," Tetrahedron, Vol. 46, No. 15, 1990, pp. 5043-5054. doi:10.1016/S0040-4020(01)87811-X

[24] E. Lattmann, S. Dunn, S. Niamsanit and N. Sattayasai, "Synthesis and Antibacterial Activities of 5-Hydroxy-4Amino-2(5H)-Furanones," Bioorganic \& Medicinal Chemistry Letters, Vol. 15, No. 4, 2005, pp. 919-921. doi:10.1016/j.bmcl.2004.12.051

[25] D. Xie, M. Faddah and J.-G. Park, "Novel Amino Acid Modified Zinc Polycarboxylates for Improved Dental Cements," Dental Materials, Vol. 21, No. 8, 2005, pp. 739-748. doi:10.1016/j.dental.2005.01.008

[26] J. B. Jones and J. M. Young, "Carcinogenicity of Lactones III: The Reactions of Unsaturated 4-Lactones with 1-Cysteine," Journal of Medicinal Chemistry, Vol. 11, No. 6, 1968, pp. 1176-1182. doi:10.1021/jm00312a017

[27] J. L. Drummond, "Degradation, Fatigue, and Failure of Resin Dental Composite Materials," Journal of Dental Research, Vol. 87, No. 8, 2008, pp. 710-719. doi: $10.1177 / 154405910808700802$ 